of surrounding DNA, and by other "local climates", as Danchin puts it, that might influence their tempo and mode of evolution or level of expression.

Early and overly simplistic notions that the determination of a genome sequence (or "genome text", in Danchin's words) will determine precisely how an organism works have long gone the way of the dodo. In silico analyses - computer analyses of genomic information as an alternative to in vivo or in vitro studies - are now an established field, known as bioinformatics. They are largely based on comparative (evolutionary) approaches. The hardest route, but in my opinion the one that offers the brightest future and the most intellectual profit, might be comparative and functional-genomic analyses of the architecture of genetic cascades and networks. The hope, and there are encouraging signs for this, is that there are commonalities and higher-level organizational principles, or even that this field of enquiry might reveal some of biology's more elusive laws.

Of course, no book can be written for everybody, but many readers might like to know what, if anything, genomics can tell us about the meaning of life. Various features of this book will be of varying interest to different audiences. Given the big issues it addresses, The Delphic Boat is apparently intended for a wide, non-specialist readership. Descriptions of the idiosyncrasies, foibles, imperfections and particular aspects of the politics of French grant-funding agencies make the book a lively read and demonstrate to the uninitiated reader that politics has an unpleasantly large role in science. Danchin also stresses the important contributions of French researchers to the various advances in genomics.

Although these often rather personal and historical sidelines might be of particular interest to science historians or researchers working on microbial genomics, these specialist readers would not want to be bothered with explanations of how the polymerase chain reaction works, for example. But such techniques and other introductory and background information will presumably be of interest to the non-specialist reader who would like to discover what genomics is all about. This kind of reader might need more explanation of some of the basic concepts in genetics and genomics, however. In some places, rather specific jargon is used which might confuse general readers. And discussion of alternative DNA-sequencing techniques is probably beyond most uninitiated readers. 'Automatic' sequencing techniques have been used pretty much exclusively in genomics for 15 years now, but one of the few figures in the book shows a 'manual' gel with radioactively labelled DNA rather a relic of the past. The lay reader would have profited from the inclusion of

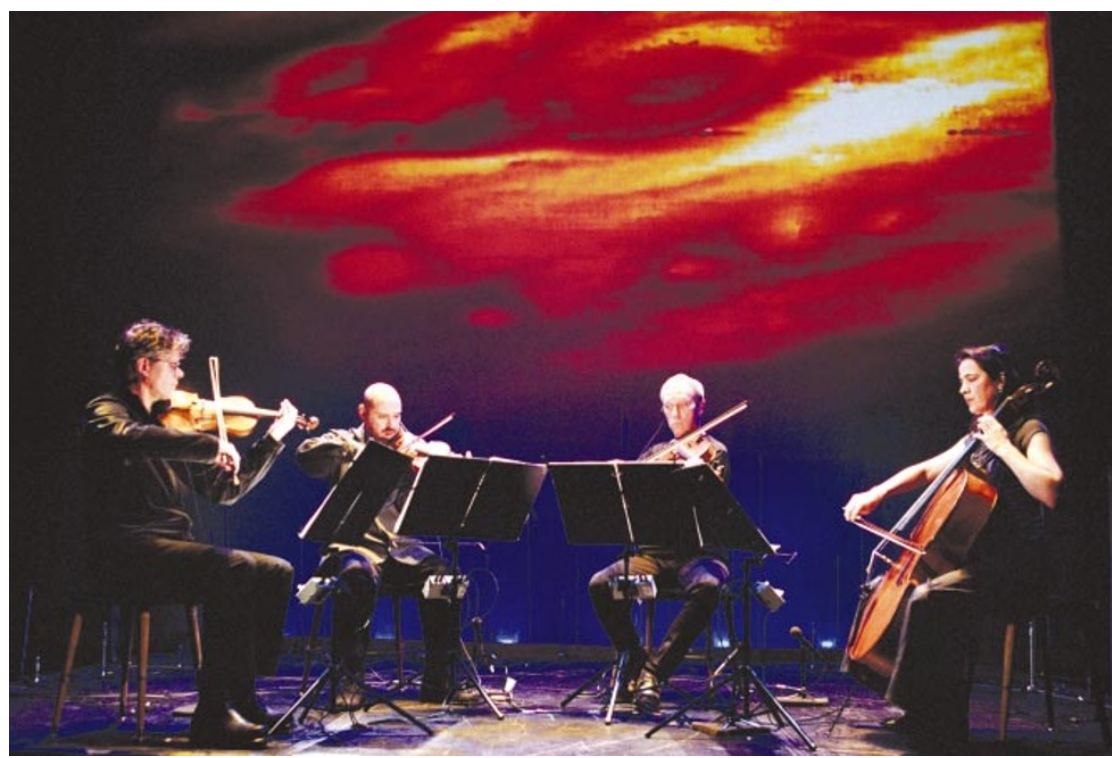

String theory? The Kronos Quartet perform Sun Rings against a backdrop of images of the Universe.

an electropherogram instead, if the budget had stretched to colour figures.

These limitations aside, Danchin provides an authoritative and impressively multidisciplinary treatment of many aspects of genomics, and his provocative thinking about the raison d'être captured my interest. I suspect that it will do the same for many readers from a large number of scientific disciplines, not only biological ones. Axel Meyer is in the Department of Biology, University of Konstanz, 78457 Konstanz, Germany.

Music

\section{Sounds from space}

\section{Sun Rings}

by Terry Riley

Performed by the Kronos Quartet

\section{Juliane C. Mössinger}

During the First World War, the German physicist Heinrich Barkhausen accidentally made the first recording of strange 'whistling' sounds while tapping British phones. He reported the peculiar tones (Phys. Z. 20, 401; 1919), but could not explain them at the time.

The 'whistler' is just one of many space sounds that form the inspiration for Terry Riley's composition Sun Rings, performed by the Kronos Quartet at the Barbican Centre in London on 22 March 2003, with further performances to follow in seven US cities over the coming months. The work, which was commissioned by NASA's arts programme, is based on the collected space recordings of Don Gurnett, an astrophysicist at Iowa State University, whose plasma-wave receivers have been travelling on various spacecraft for the past 40 years.

Plasma waves are in low radio frequencies. When converted to audible sound waves, patterns emerge - like the 'whistler', a rapidly descending tone caused by lightning discharges. Another is the 'dawn chorus', brief, rising-frequency tones that sound like the chirping of birds and which are produced by electrons trapped in magnetic fields surrounding planets.

For the performance, the theatre is plunged into darkness. The quartet on stage is surrounded by thin silver sticks adorned with dimly glowing, star-like lamps. Behind the musicians, digital images of edited and original NASA footage, arranged by visual designer Willie Williams, are projected onto a giant screen.

The ten 'spacescapes' that make up Sun Rings incorporate the original sounds recorded by the plasma-wave receivers. The string quartet also mimics them. But Riley's interesting and diverse composition is much more than this. He has done what scientists consider unthinkable, explained Gurnett in his pre-performance talk: he has manipulated original data and changed them beyond recognition. Riley's journey is largely about humans as they explore outer space to gain an awareness of their Solar System neighbourhood. The human dimension is emphasized by the addition of a choir in some of the movements.

'One Earth, one people, one love', a female voice declares. Images about life on Earth are displayed on the huge screen behind the Kronos Quartet. They are part of the message sent on Voyager through space. While bombs are dropping on Iraq, 'one Earth, one people, one love' seems to be further away from humanity than Voyager could ever travel.

Juliane C. Mössinger is a physics editor at Nature. 